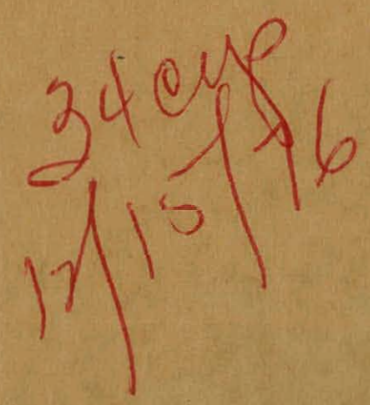

WAPD-TM-1279 ERDA RESEARCH AND DEVELOPMENT REPORT

MEASUREMENT OF THE THORIUM ABSORPTION CROSS SECTION SHAPE NEAR THERMAL ENERGY

(LWBR Development Program)

NOVEMBER 1976

CONTRACT EY-76-C-11-0014 


\section{DISCLAIMER}

This report was prepared as an account of work sponsored by an agency of the United States Government. Neither the United States Government nor any agency Thereof, nor any of their employees, makes any warranty, express or implied, or assumes any legal liability or responsibility for the accuracy, completeness, or usefulness of any information, apparatus, product, or process disclosed, or represents that its use would not infringe privately owned rights. Reference herein to any specific commercial product, process, or service by trade name, trademark, manufacturer, or otherwise does not necessarily constitute or imply its endorsement, recommendation, or favoring by the United States Government or any agency thereof. The views and opinions of authors expressed herein do not necessarily state or reflect those of the United States Government or any agency thereof. 


\section{DISCLAIMER}

Portions of this document may be illegible in electronic image products. Images are produced from the best available original document. 


\section{MEASUREMENT OF THE THORIUM ABSORPTION CROSS SECTION SHAPE NEAR THERMAL ENERGY \\ (LWBR Development Program)}

L. Green

November 1976

Contract EY-76-C-11-0014

Printed in the United States of America

Available from the

National Technical Information Service

U.S. Department of Commerce 5285 Port Royal Road

Springfield, Virginia 22151

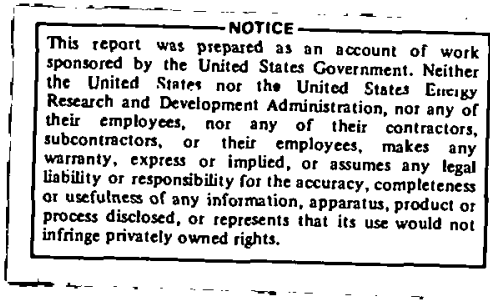

NOTE

This document is an interim memorandum prepared primarily for in ternal reference and does not represent a final expression of the opinion of Westinghouse. When this memorandum is distributed externally, it is with the express understanding that Westinghouse makes no representation as to completeness, accuracy, or usability of information contained therein.

\section{BETTIS ATOMIC POWER LABORATORY} WEST MIFFLIN, PENNSYLVȦNIA

Operated for the U.S. Energy Research anA Development Administration by 


\section{NOTICE}

This report was prepared as an account of work sponsored by the United States Government. Neither the United States, nor the United States Energy Research and Development Administration, nor any of their employees, nor any of their contractors, subcontractors, or their employees, makes any warranty, express or implied, or assumes any legal liability or responsibility for the accuracy, completeness or usefulness of any information, apparatus, product or process disclosed, or represents that its use would not infringe privately owned rights. 


\section{INTRODUCTION}

II. EXPERMMENTAL METHOD

A. Irradiation System

B. Foil Parameters

C. Counting System

D. Spectrum Calculations

III. RESULTS AND ANALYSIS 1

A. g-Factors from the Room Temperature Epithermal Index 3

1. Westcott Formalism

2. Epithermal Index for Room Temperature Polyethylene Assembly

3. Westcott g-Factors

B. Thorium g-Factor from Subcadmium Activation Ratios

C. Thorium g-Factor from $\mathrm{Ge}(\mathrm{Li})$ Detector Calibration

\section{LIST OF ILLUSTRATIONS}

\section{Figure}

\section{Title}

$1 \quad$ Irradiation System

2 Room Temperature Polyethylene Flux $\left(\mathrm{T}_{\mathrm{m}}=0.0253 \mathrm{eV}\right)$

3 Liquid Nitrogen Temperature Polyethylene Flux $\left(\mathrm{T}_{\mathrm{m}}=0.0066 \mathrm{eV}\right)$ 


\section{LIST OF TABLES}

Table

\section{1}

2

3

4

5

6

7
Foil Datã

Title

Measurement Results

Measured g-Factors from Westcott Analysis

Thorium Subcadmium Activation Ratio Results

$\mathrm{Ge}(\mathrm{Li})$ Detector Efficiency Results

Thorium and Gold $\gamma$-Ray Efficiencies

Summary of Thornum g-kactor Kesults
Page

2

4

6

7

8

8

9 
The shape of the thorium absorption cross section near thermal energies was investigated. This shape is dominated by one or more negative energy resonances whose parameters are not directly known, but must be inferred from higher energy data. Since the integral quantity most conveniently describing the thermal cross section shape is the Westcottg-factor, effort was directed toward establishing this quantity to high precision. Three nearly independent g-factor estimates were obtained from measurements on a variety of foils in three different neutron spectra provided by polyethylene-moderated neutrons from a ${ }^{252} \mathrm{Cf}$ source and from irradiations in the National Bureau of Standards "Standard Thermal Neutron Density." The weighted average of the three measurements was $0.993 \pm 0.004$. This is in good agreement with two recent evaluations and supports the adequacy of the current cross section descriptions.

\title{
MEASUREMENT OF THE THORIUM ABSORPTION CROSS SECTION SHAPE NEAR THERMAL ENERGY (LWBR Development Program)
}

\author{
L. Green
}

\section{INTRODUCTION}

Despite its importance in the calculation of reaction rates in thorium systems, there have been virtually no measurements reported of the thorium neutron capture cross section shape near thermal energies (less than about $\mathrm{leV}$ ). The only notable exception is the work of Lundgren (Reference 1), who used a fast chopper and prompt capture $\gamma$-ray detection for measurements between 0.1 and $3.4 \mathrm{eV}$. The scarcity of low energy data for thorium probably stems from the fact that high energy $\gamma$ rays are emitted in the decay of its daughter products. This has led to the need for chemical separation and a frequent change of targets to avoid unacceptably high backgrounds.

In the absence of direct measurements, the thermal cross section shape has been inferred from the well-known value at $0.0253 \mathrm{eV}(7.40$ \pm 0.08 barns), along with total cross section data through the resonance energy range. However, the capture contribution of the known positive energy levels is only about 0.45 barn out of the 7.40-barn total at $0.0253 \mathrm{eV}$. The remainder has generally been assigned to a single negative energy resonance of fixed width, with location chosen to fit the data. This procedure was followed by Lundgren, who used his data to infer a resonance at -5.1 $\pm 0.5 \mathrm{eV}$ and a room temperature Westcott gfactor of 0.995 .

Steen, in a recent evaluation (Reference 2), followed a somewhat different procedure. He assumed a resonance structure at negative energies identical to that at positive energies. In particular, the negative energy resonances were all assigned the average reduced neutron width, $\bar{\Gamma}_{n o}$ and radiative capture width, $\Gamma_{\gamma}$, and had a uniform spacing, $\overline{\mathrm{D}}$. This procedure yielded 13 significant resonances, from -16 to $-212 \mathrm{eV}$, contributing about 10 percent to the $0.0253-\mathrm{eV}$ absorption cross section. The remainder was attributed to a "floating" level at $-4.7 \mathrm{eV}$, in good agreement with the independent experimental work of Lundgren. The resulting Westcott g-factor was 0.996 .

The ENDF/B-IV evaluation (MAT 1117) depends heavily on the work of Lundgren and ther efore lists a g-factor of 0.995 .

Some doubt concerning the validity of the thorium absorption cross section shape at low thermal energies was reported recently in the work of Gunst et al. (Reference 3). These workers, utilizing data close to ENDF/B values in the thermal range, calculated reactivity worths of mixed ${ }^{233} \mathrm{U}-232 \mathrm{Th}$ samples and found significant disagreement with experiment. They found, in particular, that the fission worth of ${ }^{233} \mathrm{U}$ in the presence of $\mathrm{ThO}_{2}$ was 10 percent less than calculated. One possible explanation offered for this discrepancy was that 232 I'h absorption departs significantly from $1 / v$ behavior at low energy. Therefore, the shielding of the ${ }^{233} \mathrm{U}$ by the preponderant ${ }^{232} \mathrm{Th}$ would not be correctly described by the shielding model used in the calculation.

The present work was undertaken to provide more direct information on the thorium thermal absorption cross section shape than that inferred from the higher energy data. In particular, the nearly $1 / v$ dependence below $0.1 \mathrm{eV}$ predicted by current evaluations was examined.

\section{EXPERIMENTAL METHOD}

The experiment consisted of the irradiation of thorium metal foils along with several $1 / v$ and non 
$1 / v$ absorbers in the polyethylene-moderated spectrum from a ${ }^{252} \mathrm{Cf}$ spontaneous fission source. Irradiations were performed with the polyethylene at room temperature, at liquid nitrogen temperature, and poisoned with boron ( $9.88 \mathrm{~b}$ /hydrogen atom), providing three different incident neutron spectra. Both bare and cadmium-covered data were taken. From the saturated foil activities measured with a $\mathrm{Ge}(\mathrm{Li}) \gamma$-ray detector information was extracted about the thermal cross section shape. Details of the experiment follow.

\section{A. Irradiation System}

The foils were irradiated near the center of a polyethylene cylinder 17.8 centimeters high and 17.8 centimeters in diameter, as shown in Figure 1. The ${ }^{252} \mathrm{Cf}$ source used was the same as that described in Reference 4 and had an emission rate of approximately $10^{8} \mathrm{n} / \mathrm{sec}$ at the time of these measurements. The considerations in the design of the foll holder were the reproducibility of foil position and the ease and speed of recovery of the foil package. The latter was especially important in counting the $3.76-$ minute $52 \mathrm{~V}$ activity. The polyethylene cylinder was placed inside a Dewar, which was kept filled with liquid nitrogen by an automatic filling system for the cold measurements. For these measurements the foil holder was first cooled to liquid nitrogen temperature in a second Dewar before insertion into the irradiation Dewar.

For the boron-poisoned measurements, a cylinder and foil holder identical to those in Figure 1 were machined from polyethylene containing 2.05 percent boron by weight as a uniform (to \pm 5 percent) dispersinn

\section{B. Foil Parameters}

A list of all foils used, along with some pertinent data, is given in Table 1. Each irradiation consisted of a foil package containing. all tive foils, with the thorium foil in the center. The foil order was reversed in half the measurements and the results averaged. All foils were 1.27 centimeters in diameter. The cadmium-covered irradiations were conducted with identical foil packages inside a 0.090-millimeter-thick cadmium box. Aluminum spacers were used to locate the foils in the same locations for the bare measurements.

\section{Counting System}

The $\gamma$-activity of each of the foils was measured by placinq them in contact with the front fare of a 5.-rm ${ }^{3}$ marial $\mathrm{Ge}(\mathrm{Li})$ detoctor. The aroa bencath the peaks listed in Table 1 was then determined from the counting data accumulated in a 1024channel pulse height analyzer. $\bar{A} \mathrm{NaI}(\mathrm{Tl}) \mathrm{Compton}$ anticoincidence annulus was used in counting the thorium foils in order to suppress the background from the decay of thorium and its daughter products. This system reduced the Compton background in the vicinity of the ${ }^{233} \mathrm{~Pa}$ peak a factor of 3 , while reducing the $311-\mathrm{keV}$ peak area only 3 percent.

\section{Spectrum Calculations}

The three irradiation spectra were calculated at the foil package location by a Monte Carlo program (Reference 5) extended to three dimensions and tho full noutron energy range. The Ealuulaliun

TABLE 1. FOIL DATA.

\begin{tabular}{|c|c|c|c|c|}
\hline Isotope & Foil Form & Thirlenoss (mm) & Aativity & $\begin{array}{c}\gamma \text {-Ray Peak } \\
\text { Counted (heV) }\end{array}$ \\
\hline${ }^{232} \mathrm{Th}$ & Pure metal & 0.140 & $27.2-$ day ${ }^{233} \mathrm{~Pa}$ & 311 \\
\hline${ }^{197} \mathbf{A u}$ & 3 w/o Au In $N_{1}$ & 0.102 & $64.7-h_{12}{ }^{188} \mathrm{Au}$ & 412 \\
\hline${ }^{51} \mathrm{~V}$ & Pure metal & 0.127 & $3.76-\min { }^{52} \mathrm{~V}$ & 1434 \\
\hline${ }^{55} \mathrm{Mn}$ & $79 \mathrm{w} / \mathrm{o} \mathrm{Mn}$ in $\mathrm{Cu}$ & 0.0635 & $2.579-\mathrm{hr}{ }^{56} \mathrm{Mn}$ & 847 \\
\hline${ }^{63} \mathrm{Cu}$ & $79 \mathrm{w} / \mathrm{o} \mathrm{Mn}$ in $\mathrm{Cu}$ & 0.0635 & $12.74-\mathrm{h}_{\mathrm{\prime r}}{ }^{64} \mathrm{Cu}$ & 511 \\
\hline${ }^{175} \mathrm{Lu}$ & $10 \mathrm{w} / \mathrm{o} \mathrm{Lu}$ in $\mathrm{Al}$ & 0.127 & $3.69-\mathrm{hr}{ }^{176} \mathrm{Lu}$ & 88 \\
\hline${ }^{176} \mathrm{Lu}$ & $10 \mathrm{w} / \mathrm{o} \mathrm{Lu}$ in $\mathrm{Al}$ & 0.127 & 6.71 -day ${ }^{177} \mathrm{Lu}$ & 113 \\
\hline
\end{tabular}


provided the flux in 54 last ( $10 \mathrm{MeV}$ to $0.625 \mathrm{eV}$ ) and 25 thermal $(0.625 \mathrm{eV}$ to 0$)$ groups. To obtain adequate statistics it was necessary to represent the foil region as a spherical shell having the thickness of the foil package ( 0.053 centimeter) and centered at the source. The polyethylene cylinder was represented as being in a vacuum, i.e., having nonreflecting boundaries. This is not quite correct, since up to 60 percent of the neutrons leak from the assemblies, and some of these must return. The return was simulated in the calculation by increasing the cylinder radius from its actual value of 8.89 centimeters to 10 centimeters. This was calculated to be equivalent to about a 20 percent room return and was considered reasonable. The difference in the temperature of the Maxwellian energy distributions was less than $0.001 \mathrm{eV}$ at the two radii and introduced a negligible uncertainty into the subsequent analyses.

The thermal scattering cross sections used in the Monte Carlo calculation for polyethylene were calculated at room temperature $\left(296^{\circ} \mathrm{K}\right.$, $0.0253 \mathrm{eV}$ ) and at liquid nitrogen temperature $\left(77^{\circ} \mathrm{K}, 0.0066 \mathrm{eV}\right)$ from the four-oscillat or model of Koppel and Young (Reference 6). Scattering matrices from this model were generated by a program essentially identical to the GAKER code (Reference 7). Neutron spectra calculated from the Koppel and Young-GAKER formalism have been shown to be in good agreement with experimentally measured spectra (References 6, 8, and 9). The carbon cross sections used were those in ENDF/B-IV, MAT 1165.

The calculated spectra in the thermal range are displayed in Figures 2, 3, and 4. Maxwellians obtained from least squares fit to the points in the region of the thermal peaks are also shown. The data have been area normalized. It may be seen that the neutron temperature is somewhat lower than the moderator temperature, $T_{m}$, for the two unpoisoned cases, a consequence of diffusion cooling of the highly leaking assemblies.

It can be seen from Figure 4 that the Maxwellian distribution, with a temperature of $0.034 \mathrm{l} \mathrm{eV}$, provides a good fit to the thermal data for the boronpoisoned assembly. This phenomenon, i.e., that the addition of a $1 / \mathrm{v}$ absorber to a moderator results in a Maxwellian thermal distribution with a temperature higher than the moderator temperature, has been observed by a number of authors (References 10,11, and 12). This provides a convenient technique for the measurement of reaction rates in different, but well-defined neutron spectra. The primary limitation is the lower activation resulting from the addition of the absorber.

Figure 5 is a plot of the product $\mathrm{E} \varphi(\mathrm{E})$ versus energy through the resonance energy range. It can be seen that the flux varies very closely as $1 / \mathrm{E}$ through this range, except for the small rise below
$10 \mathrm{eV}$. This is of consequence only for the gold foil, since 95 percent of gold absorptions occur in the narrow resonance at $4.9 \mathrm{eV}$. The flux rise is 2 percent at this energy, and a correction for this was made where required.

\section{RESULTS AND ANALYSIS}

Eight irradiations were conducted for each assembly, four bare and four cadmium covered. Irradiation times varied from 1 to 14 days. Table 2 summarizes the cadmium ratio and cadmium difference results obtained, corrected for background, foil decay, saturation, and ${ }^{252} \mathrm{Cf}$ source decay. It may be observed that the cadmium ratios for the $1 / v(V, M n, C u)$ and near $1 / v\left(A u,{ }^{175} \mathrm{Lu}\right) \mathrm{ab}$ sorbers increase in cooling the assembly, as expected. In contrast, the ratio for ${ }^{176} \mathrm{Lu}$, which has a g-factor of 1.75 , decreases nearly 60 percent as the neutron distribution moves further from the principal $0.14-\mathrm{eV}$ resonance. This property of ${ }^{176} \mathrm{Lu}$ has made it useful as a probe for the measurement of neutron temperatures (References 13 and 14). It is used here to demonstrate the sensitivity of the techniques employed to the presence of a resonance near thermal energies. It may also be seen from Table 2 that there is an average increase (for the $1 / \mathrm{v}$ absorbers) of ab out 9 percent in the cadmium difference (thermal) signal in cooling the polyethylene to liquid nitrogen temperature. For a $l / v$ absorber, the reaction rate is independent of flux shape, depending only upon the total neutron density. The density increases in this case because of reduced leakage for the cooled assembly. The 10 percent reduction in thermal leakage predicted by the Monte Carlo calculation is in excellent agreement with the observed 9 percent change.

The data in Table 2 were used to obtain two nearly independent estimates of the thorium room temperature Westcott g-factor, as well as the gfactors for several other absorbers. In addition, a third g-factor estimate was obtained from irradiation data on thorium and gold from an earlier study (Reference 4). These are described in Sections III.A through III.C.

\section{A. g-Factors from the Room Temper- ature Epithermal Index}

\section{Westcott Formalism}

The shape of the absorption cross section near thermal for an arbitrary isctope is conveniently represented by the Westcott g-facior (Reference 15), which is defined by the relation

$$
R_{m}=n v_{0} \sigma_{0} g .
$$




\section{TABLE 2. MEASUREMENT RESULTS}

\begin{tabular}{|c|c|c|c|c|c|c|c|}
\hline & \multicolumn{7}{|c|}{ Cadmium Ratios } \\
\hline & $\underline{\mathbf{V}}$ & $\underline{M_{n}}$ & $\underline{\mathrm{Au}}$ & Th & Cu & ${ }^{175} \underline{\mathrm{Lu}}$ & ${ }^{176} \underline{\mathrm{Lu}}$ \\
\hline Room temperature & $72.99 \pm 0.61$ & $39.04 \pm 0.42$ & $4.13 \pm 0.02$ & $6.15 \pm 0.05$ & $\Xi 7.15 \pm 1.67$ & $2.23 \pm 0.03$ & $160.8 \pm 6.7$ \\
\hline Liquid nitrcgen temperatire & $82.98 \pm 1.35$ & $45.34=0.73$ & $4.50 \pm 0.01$ & $7.73 \pm 0.015$ & $42.42 \pm 1.26$ & $2.32 \pm 0.03$ & $93.94 \pm 2.24$ \\
\hline \multirow[t]{2}{*}{ Boron-poisoned assembly } & $3.76 \pm 0.29$ & $2.42=0.04$ & $1.117 \pm 0.003$ & $1.192 \pm 0.604$ & $2.2 \leftarrow \pm 0.06$ & $1.035 \pm 0.019$ & $11.80 \pm 0.25$ \\
\hline & \multicolumn{7}{|c|}{ Cadmium Difference (ccints/mir/g) } \\
\hline Room temperature & $39,5 \supset 9 \pm 190$ & $129,043 \pm 298$ & $39,186 \pm 83$ & $26,447 \pm 1683$ & $4357 \pm 26$ & $4380 \pm 57$ & $18,681 \pm 119$ \\
\hline Liquid nitrogen temperature & $4 \hat{a}, 4 \overline{5} 5 \pm 386$ & $142,569 \pm 201$ & $4:, 931 \pm 77$ & $29,268 \pm 163$ & $\leq 892 \pm 18$ & $5019 \pm 125$ & $10,958 \pm 72$ \\
\hline Boron-poisoned assembly & $1372 \pm 52$ & $4353 \pm 75$ & $1302 \pm 32$ & $906 \pm 21$. & $14 \% . \overline{2} \pm 5.1$ & $128 \pm 68$ & $1087 \pm 22$ \\
\hline
\end{tabular}


$R_{m}$ is the reaction rate of a foil in a pure Maxwellian spectrum, having a cross section $\sigma_{o}$ at the most probable velocity $v_{0}$ of the Maxwellian distribution. Generally, $v_{0}$ is taken to be $2200 \mathrm{~m} / \mathrm{sec}$, the most probable velocity at $296^{\circ} \mathrm{K}$. For a foil whose cross section varies as $1 / v$ through the thermal range, $g$ may be shown to be identically equal to 1 . Therefore, the " $1 / v$ ness" of a foil is expressed by the departure of $g$ from unity. Westcott $g$-factors are usially calculated from measured resonance parameters. In the case of thorium, the material of i primary interest here, $g$ is almost completely determined by the inferred negative energy resonance.

For a mixed incident spectrum, the reaction rate in the Westcott formalism is expressed as

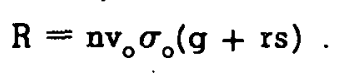

Expressions for $r$ and $s$ may be identified by assuming that the spectrum can be expressed as the sum of a Maxwellian and a $1 / \mathrm{E}$ distribution, i.e.,

$$
\varphi(E)-\varphi_{\mathrm{t}} \frac{\mathrm{E}}{\left(\mathrm{kT}_{\mathrm{o}}\right)^{2}} \mathrm{e}^{-\mathrm{E} / \mathrm{kT} \mathrm{o}}+\varphi_{\mathrm{e}} \frac{\Delta(\mathrm{E})}{\mathrm{E}}
$$

where $\varphi_{t}$ is the total thermal flux and $\varphi_{e}$ the epithermal flux per unit energy interval, $k$ is the Boltzmann constant, and $\Delta(E)$ is the joining function, which may take a variety of forms (Reference 16). For the purpose here, it is adequate to assume the simple form

$$
\begin{aligned}
& \Delta(E)=1 \text { for } E>\mu k T \\
& \Delta(E)=0 \text { for } E<\mu k T .
\end{aligned}
$$

The value of $\mu$ is usually about 5 . If a factor $\mathrm{f}$ is also defined such that

$$
£ \equiv \frac{\varphi_{\mathrm{e}}}{\varphi_{\mathrm{t}}+\varphi_{\mathrm{e}}},
$$

it may be shown that

$$
r=\frac{\mathrm{f} \sqrt{\pi \mu}}{4}
$$

and

$$
=\frac{2 \mathrm{I}^{\prime}}{\sqrt{\pi} \sigma_{0}} \sqrt{\frac{\mathrm{T}}{\mathrm{T}}}
$$

where

$$
I=\int_{\mu \mathrm{kT}}^{\infty}\left[\sigma(E)-g \sqrt{\frac{E_{0}}{E}} \sigma_{0}\right] \frac{d E}{E} .
$$

For $g$ close to unity the lower limit on the integral may be taken as the cadmium cutoff energy. $I^{\prime}$ is then just the resonance intergral with the $1 / v$ part (multiplied by g) subtracted out.

The epithermal index, $r$ may be expressed in terms of the cadium ratio, $\mathrm{R}_{c d}$ as

$$
R_{c d}=\frac{g+r s}{r}\left[s+\frac{1}{K} \sqrt{\frac{T}{T_{0}}}\right]^{-1} .
$$

$\mathrm{K}$ is a constant depending only upon the cadmium cutoff and equal to 0.4739 here. Rearranging terms in Equation (8) yields

$$
\mathrm{r}=\frac{\mathrm{g}}{\mathrm{R}_{\mathrm{cd}} \boldsymbol{\beta}-\mathrm{s}}
$$

where

$$
\beta \equiv \mathrm{s}+\frac{1}{\mathrm{~K}} \sqrt{\frac{\mathrm{T}}{\mathrm{T}_{\mathrm{o}}}} .
$$

In the present analysis the gold foil data are used to obtain the epithermal index, $r$, for the room temperature polyethylene assembly. This index is then used to arrive at a room temperature $\mathrm{g}$-factor for thorium. As a check on the procedure, g-factors are also calculated for the other foils.

\section{Epithermal Index for Room Tempera- ture Polyethylene Assembly}

The epithermal index is calculated from Equations (6), (7), and (9) using the gold-cadmium ratio listed in Table 2 . This value, including 1 percent correction for resonance overlap with cadmium, is 4.09. All resonance integrals in this work are taken from Reference 17, which lists a value of 1560 barns for gold. This becomes 1591 barns when the effect of the flux rise at $4.9 \mathrm{eV}$ referred to earlier is included. The resonance self-shielding factor, from the data of Baumann (Reference 18), is 0.780 , giving a total effective resonance integral of 1241 barns. The $1 / v$ contribution, obtained for a gold cadmium cutoff of $0.60 \mathrm{eV}$, is 41 barns so that $I^{\prime}=1200$ barns. Equation (6) then yields a value for $\mathrm{s}$ of 13.212 at $\mathrm{T}=0.02353 \mathrm{eV}$. Substituting into Equations (9) and (10), with $g_{A u}=1.005$, finally yields

$$
r=0.02354 \pm 0.00021
$$

\section{Westcott g-Factors}

The g-factors calculated from the measured cadmium ratios and the epithermal indez from the gold data, Equation (11), are listed in Table 3, along with the cross section parameters used in the analysis. As indicated earlier all cross sections 
TABLE 3. MEASURED g-FACTORS FROM WESTCOTT ANALYSIS

\begin{tabular}{|c|c|c|c|c|c|}
\hline g-Factor & $\mathbf{v}$ & $\mathbf{M n}$ & $\mathrm{Cu}$ & ${ }^{175} \mathrm{Lu}$ & Th \\
\hline $\begin{array}{c}\mathbf{g} \\
\text { (measured) }\end{array}$ & $1.000 \pm 0.005$ & $1.002 \pm 0.003$ & $1.002 \pm 0.010$ & $0.972 \pm 0.005$ & $0.987 \pm 0.005$ \\
\hline$\frac{\mathrm{g}}{(\mathrm{ENDF} / \mathrm{B}-\mathrm{IV})}$ & 1.000 & 1.000 & 1.000 & 0.977 & 0.995 \\
\hline $\begin{array}{c}\text { Cruss 3eclius } \\
\text { Parameter }\end{array}$ & V & $\mathrm{Mn}$ & $\mathrm{Cu}$ & ${ }^{175} \mathrm{Lu}$ & Th \\
\hline$\sigma_{\circ}$ (barns) & $4.88 \pm 0.04$ & $13.3 \pm 0.2$ & $4.5 \pm 0.1$ & $13.26 \pm 0.53$ & $7.4 \pm 0.08$ \\
\hline I (barns) & $2.7 \pm 0.1$ & $14.0 \pm 0.4$ & $4.9 \pm 0.4$ & $405 \pm 15$ & $85.5 \pm 3.0$ \\
\hline$I_{1 / v}$ (barns) & $2.13 \pm 0.08$ & $5.81 \pm 0.20$ & $1.97 \pm 0.08$ & $5.7 \pm 0.1$ & $1.51 \pm 0.50$ \\
\hline$s$ & 0.12706 & 0.6496 & 0.7083 & 32.758 & 7.532 \\
\hline
\end{tabular}

are from Reference 17, except those for ${ }^{175} \mathrm{Lu}$, which are taken from the measurements of Gibello et al. (Reference 19). The g-factor errors include uncertainties in the cadmium ratio, resonance integral, $1 / \mathrm{v}$ contribution, and (for manganese and thorium) resonance self-shielding. The uncertainty in $r$ of 0.89 percent has not been included, since it would be observed as a systematic error.

The analysis for manganese includes a 3 percent self-shielding factor, calculated from the first two manganese resonances by the method of Baumann (Reference 18). Self-shielding of the other resonances was estimated and found to be negligible. The resonance self-shielding factor for the thorium toils was $\dot{0.61} \pm 0.01$ from the data of Brose (Reference 20). A 0.7 percent correction to the cadmium ratio for internal thermal flux depression was also included for thorium. The $1 / \mathrm{v}$ contribution to the thorium resonance integral was calculated from

$$
I_{1 / v}=\int_{\dot{U} 53}^{\dot{\omega}} \frac{E_{O}}{E}\left[6.95 \frac{\left(E_{O}-\bar{E}_{\mathrm{r}}\right)^{2}}{\left(F_{\mathrm{r}}-F_{\mathrm{r}}\right)^{2}}+0.45\right] \frac{\mathrm{dE}}{\mathrm{E}} .
$$

$\mathrm{k}_{\mathrm{r}}$ is the location of the negative energy resonance $(-5 \mathrm{eV})$, and the first term in the integral is the contribution from this resonance. The second term is the contribution of the positive energy resonances with cross section 0.45 barn at $\mathrm{E}_{\text {o }}$.

The g-factors obtained for the three $1 / \mathrm{v}$ absorbers, $\mathrm{V}, \mathrm{Mn}$, and $\mathrm{Cu}$, are all seen to be unity within experimental error, providing confidence that no significant systematic errors are being introduced (especially through the epithermal index, r). The weighted average of the three is $1.001 \pm 0.002$.

The $g$-factor for ${ }^{175} \mathrm{Lu}$ is in excellent agreement with the value of 0.977 listed in ENDF/B-IV (Reference 21). The value for ${ }^{176} \mathrm{Lu}$ cannot be obtained in this simplified analysis because its resonance near thermal violates the condition that the cross sections vary as $1 / v$ between the beginning of the epithermal distributions, $\mu \mathrm{kT}$, and the cadium cutoff.

The g-factor for thorium is seen to be lower than the ENDF/B value, but does not exclude it.

\section{B. Thorium g-Factor from Subcad- mium Activation Ratios}

The g-factor for thorium was next examined by forming the ratio of the subcadmium activation rate of thorium to each of the three $1 / \mathrm{v}$ absorbers for the different irradiation spectra. These are listed in the upper part of Table 4. These ratios are proportivial lo the g-factors for therium and would re. main constant if thorium were also a $1 / \mathrm{v}$ absorber. The ronstancy was tested by examining the ratios listed in the lower part of the table. These are just the ratios of the g-factors for thorium for the various test cases. It may be seen that, within experimental error, no variation was observed. The uncertainties for the boron-poisoned cases are large because of low cadmium ratios. It should be pointed out that both the Steen and ENDF/B-IV evaluations predict a $\mathrm{g}$-factor of essentially $\mathrm{l}$ at liquid nitrogen temperature, decreasing by 0.3 percent and 0.8 percent for the room temperature and boron-poisoned assembly temperature cases, respectively. These changes are too small to be observed here. 


\begin{tabular}{|c|c|}
\hline & $\mathbf{M n}$ \\
\hline$L N^{*}$ & $0.2053 \pm 0.0011$ \\
\hline $\mathrm{RT}^{* *}$ & $0.2049 \pm 0.0014$ \\
\hline $\mathrm{BP} * * *$ & $0.2081 \pm 0.0060$ \\
\hline LN/RT & $1.002 \pm 0.009$ \\
\hline RT/BP & $0.985 \pm 0.030$ \\
\hline LN/BP & $0.986 \pm 0.030$ \\
\hline
\end{tabular}

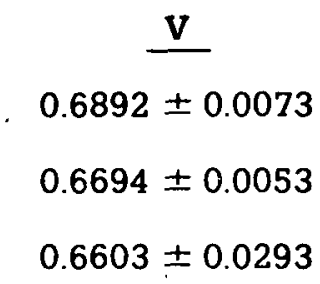

$1.029 \pm 0.014$

$1.014 \pm 0.046$

$1.044 \pm 0.065$
$\underline{\mathrm{Cu}}$
$5.983 \pm 0.040$
$6.056 \pm 0.053$
$6.15 \pm 0.25$

Weighted Average

$0.988 \pm 0.011$

$1.003 \pm 0.006$

$0.985 \pm 0.042$

$0.991 \pm 0.020$

$0.973 \pm 0.040$
An estimate of the room temperature g-factor may be obtained from the ratio

$$
\begin{aligned}
& \qquad \mathrm{LN} / \mathrm{RT}=1.003 \pm 0.006 \\
& =g_{\mathrm{LN}} / \mathrm{g}_{\mathrm{RT}} \\
& \text { By setting } \mathrm{g}_{\mathrm{LN}}=1, \\
& \quad \mathrm{~g}_{\mathrm{RT}}=0.997 \pm 0.006, \quad \text { (13) } \\
& \text { in good agreement with the value of } 0.987 \pm 0.005 \\
& \text { obtained previously (Table 3). } \\
& \text { C. Thorium g-Factor from } \mathrm{Ge}(\mathrm{Li}) \\
& \text { Detector Calibration }
\end{aligned}
$$

\section{Thorium g-Factor from $\mathrm{Ge}(\mathrm{Li})$ Detector Calibration}

The National Bureau of Standards provides a "Standard Thermal Neutron Density" produced by two Ra-Bo noutron sources permanently fixed in a moderating geometry of paraffin and graphite. $\mathbf{E} x$ posures of foils are made in a cavity in the graphite. The total thermal, i.e., subcadmium, neutron density has been measured by boron films and gold foils, and is defined such that the saturated counting rate obtained for a foil irradiated in the cavity is given by

$$
\mathrm{R}=\frac{\mathrm{n}_{\mathrm{th}} \mathbf{v}_{\mathrm{o}} \sigma_{\mathrm{o}} \in \mathrm{N}_{\mathrm{A}}}{\bar{A}} \mathrm{~g}
$$

where $a_{\text {th }} v_{0}$ is the measured neutron density converted to an equivalent $2200 \mathrm{~m} / \mathrm{sec}$ flux, and was $4353 \pm 1.5 \% \mathrm{n} / \mathrm{cm}^{2}$-sec here, $\epsilon$ is the delector efficiency, $\mathbf{N}_{A}$ is Avogadro's number, and $A$ is the atomic weight of the foil. $\mathrm{R}$ must be corrected for thermal self-shielding and resonance overlap.

Thorium and gold foils were irradiated recently in the Standard Neutron Density in conjunction with a fast neutron cross section measurement program (Reference 4). The corrected count rates obtained were

$$
\begin{aligned}
& R_{T h}=1.35 \pm 0.13 \mathrm{c} / \mathrm{sec} / \mathrm{g} \\
& R_{\mathrm{Au}_{\mathrm{s}}}=46.36 \pm 0.25 \mathrm{c} / \mathrm{sec} / \mathrm{g}
\end{aligned}
$$

The gold foils were of the pure metal, 0.0635 millimeter thick, while the thorium metal foils were 0.267 millimeter thick. All foils were 2.22 centimeters in diameter. There remains now only the determination of the efficiencies for the $412-\mathrm{keV}$ gold $\gamma$-ray and the $311-\mathrm{keV}$ thorium $\gamma$-ray to obtain g directly from Equation (14).

The detector efficiency-energy dependence was measured using a number of calibrated point sources. These sources were placed in contact with the front face of the detector and rotated in position to accumulate an average count rate over a foil-equivalent area. The elficiencies obtained are listed in Table 5 and plotted on a log-log scale in Figure 6. The data have been corrected for summing, especially important for ${ }^{133} \mathrm{Ba}$. Both a linear least-squares fit and a smooth curve through the data points are also shown. The difference is only about 0.5 percent at the gold and thorium energies.

The long-term efficiency stability of the detector was examined by comparing the linear slope ob. tained here; $1.090 \pm 0.014$, with that measured by Tessler and Glickstein for the same detector in 
TABLE 5. GE(LI) DETECTOR EFFICIENCY RESULTS

\begin{tabular}{llll} 
Source & & $\begin{array}{c}\text { Energy } \\
(\mathrm{keV})\end{array}$ & \multicolumn{1}{c}{$\begin{array}{c}\text { Efficiency } \\
(\%)\end{array}$} \\
${ }^{133} \mathrm{Ba}$ & 276.46 & & 5.48 \\
${ }^{133} \mathrm{Ba}$ & 303.08 & & 5.15 \\
${ }^{133} \mathrm{Ba}$ & 356.27 & & 4.26 \\
${ }^{133} \mathrm{Ba}$ & 384.10 & & 3.88 \\
${ }^{22} \mathrm{Na}$ & 511.0 & & 2.96 \\
${ }^{137} \mathrm{Cs}$ & 661.63 & & 2.27 \\
${ }^{54} \mathrm{Mn}$ & 831.81 & 1.74 \\
${ }^{65} \mathrm{Zn}$ & 1115 & 1.21 \\
${ }^{60} \mathrm{Co}$ & 1173 & 1.16 \\
${ }^{60} \mathrm{Co}$ & 1332 & 0.99
\end{tabular}

1971 and reported in Reference 22. Their value was $1.056 \pm 0.013$, in good agreement with the present value, providing confidence that the application of the current efficiency measurements to data taken a year earlier is valid.

The efficiencies for gold and thorium, as well as the corrections that must be applied before substituting these values into Equation (14), are listed in Table 6 . The $\gamma$-ray self-shielding corrections were obtained experimentally using a series of foils of vàyiny thickness and extrapolating to zcro thickness. The annulus correction for thorium was measured by counting the $31 \mathrm{l}-\mathrm{keV}$ peak area with and without the annulus in operation. Substituting into Equation (14) and solving for g yields

$$
\begin{aligned}
& g_{\mathrm{Th}}=1.022 \pm 0.035 \\
& g_{\mathrm{Au}}=1.019 \pm 0.034
\end{aligned}
$$

1 The error estimates were obtained by combining in quadrature the uncertainties in the standard flux ( 1.5 percent), the detector efficiency ( 3 percent), and the counting statistics (1 percent for thorium and 0.5 percent for gold)

It is apparent that, while the result above for thorium is in nominal agreement with the values obtained earlier, the uncertainty is too large to make it useful. However, if the ratio of the values obtained in Equations (15a) and (15b) is formed instead, the fly r arror disappears as well as tnust of the efficiency error. The latter now reflects only the uncertainty in the energy dependence of the efficiency and not its absolute values. $\AA$ measure of this is the uncertainty in the slope of the efficiency curve, 1.3 percent. However, this is for an energy range trom $300 \mathrm{keV}$ to $1.3 \mathrm{MeV}$, while the two $\gamma$ raye buing considered dre only $100 \mathrm{keV}$ apart. Therelore, the crror is now cumpletely dnmmated by the counting statistics, and forming the ratio yields

$$
\frac{g_{T h}}{g_{A u}}=1.003 \pm 0.011
$$

With $\mathrm{g}_{A_{\mathrm{u}}}=1.005$, the thorium g-factor is

$$
\mathrm{g}_{\mathrm{Th}}=1.008 \pm 0.011 \text {. }
$$

Within statistics this is in good agreement with the two earlier values.

\section{SUMMARY AND CONCLU- SIONS}

The purpose of this stury was to provide infurmalion on the shape of the thorium absorption cross section near thermal energy. The neutronics behavior of light water systems utilizing thorium as the fertile material is very sensitive to this shape, which is currently assumed to bc dominated by one or more negalive energy (bound state) resoriares whoco parameters aut nul directly known,

\begin{tabular}{|c|c|c|c|c|c|}
\hline & $\begin{array}{c}\text { Uncorrected } \\
\text { Efficiency (\%) }\end{array}$ & $\begin{array}{l}\gamma \text {-Ray } \\
\text { Yield } \\
\end{array}$ & $\begin{array}{c}\gamma-\operatorname{Ray} \\
\text { Self-Shielding }\end{array}$ & $\begin{array}{c}\text { Annulus } \\
\text { Loss }\end{array}$ & $\begin{array}{c}\text { Net } \\
\text { Efficiency }(\%)\end{array}$ \\
\hline $\mathrm{Au}(412 \mathrm{keV})$ & 3.67 & $0.95^{*}$ & 0.9938 & - & 3.46 \\
\hline $\mathrm{Th}(311 \mathrm{keV})$ & 4.98 & $0.34^{*}$ & 0.964 & 0.968 & 1.58 \\
\hline
\end{tabular}
but must be inferred from the average properties of the positive energy resonances.

TABLE 6. THORIUM AND GOLD $\gamma$-RAY EFFICIENCIES

- Reference 23 


\section{TABLE 7. SUMMARY OF THORIUM g-FACTOR RESULTS}

\section{Method}

Use of epithermal index from gold activation

Activation ratios at room and liquid nitrogen temperatiures

NBS irradiation and detector calibration

Weighted average: $\quad 0.993 \pm 0.004$
The integral quantity most conveniently describing the thermal cross section shape is the Westcott g-factor, and effort was directed toward establishing this quantity to high precision. Three nearly independent estimates were obtained from irradiations on a variety of foils in three different neutron spectra provided by polyethylenemoderated neutrons from a ${ }^{252} \mathrm{Cf}$ source and irradiations in the National Bureau of Standards (NBS) "Standard Thermal Neutron Density." The results are summarized in Table 7 . The final value, $0.993 \pm 0.004$, is in good agreement with two recent evaluations and provides increased confidence that the cross section shape is adequately described.

\section{ACKNOWLEDGMENTS}

The assistance of $\mathrm{E}$. Schmidt in the calculations of the polyethylene scattering matrix is gratefully acknowledged. The use of liquid nitrogen temperature irradiations was suggested by S. Milani. Finally, the author is indebted to J. J. Volpe for many valuable discussions.

\section{REFERENCES}

1. G. Lundgren, "A Study of the Energy Dependence of the Th-232 Capture Cross Section in the Energy Region 0.1 to $3.4 \mathrm{eV}, "$ Nuckleonik 11, 61 (1968).

2. N. M. Steen, "An Evaluation of the Radiative Neutron Capture Cross Sections of Thorium-232 for the Range $0.0 \mathrm{eV}$ to 1.5 MeV," WAPD-TM-971, December 1970.

3. S. B. Gunst, J. C. Connor, and D. E. Conway, "Measured and Calculated Fission-Project Poisoning in Neutron-Irradiated Uranium-233," Nucl. Sci.. Eng. 58, 387 (1975).
4. L. Green, "Absorption Cross Section Measurements for Californium-252 Spontaneous Fission Neutrons," Nucl. Sci. Eng. 58, 361 (1975).

5. N. R. Candelore and R. C. Gast, "Recap-3-A Monte Carlo Program for Estimating Epi-Thermal Capture Rates in Rectangular or $60^{\circ}$ Parallelogram Geometry," WAPD-TM-437, March 1964.

6. J. V. Koppel and J. A. Young, "Neutron Scattering by Polyethylene," Nucl. Sci. Eng. 21, 268 (1965).

7. H. C. Honeck, "Thermos. A Thermalization Transport Theory Code for Reactor Lattice Calculations," Brookhaven National Laboratory, USAEC Report BNL-5826 (1961).

8. J. C. Young and D. Huffman, "Experimental and Theoretical Neutron Spectra," USAEC Report GA-5319, Gulf General Ātomic Incorporated, May 1964.

9. D. Sprevak and J. V. Koppel, "Neutron Scattering in Polyethylene," Nukleonik 12, 87 (1969).

10. K. H. Backhurts and K. Wirtz, "Neutron Physics," pp. 200-207, Springer-Verlag, New York, 1964

11. E. R. Cohen, "The Neutron Velocity Spectrum and Heavy Moderator," Nucl. Sci. Eng. 2, 227 (1957)

12. R. F. Coveyou, R. R. Bate, and R. K. Osborn, "Effect of Moderator Temperature Upon Neutron Flux in Infinite Capturing Medium," J. Nuclear Energy 2, 153 (1956).

13. L. C. Schmid and W. P. Stenson, "Calibration of Lutetium for Measurements of Effective Neutron Temperatures," Nucl. Sci. Eng. 7, 477 (1960).

14. B. G. Chidley, R. B. Turner, and C.B. Bigham, "Neutron Temperatures in a CANDU-Type Power Reactor," Nucl. Sci. Eng. 16, 39 (1963).

15. C. H. Westcott, W. H. Walker, and T. K. Alexander, "Effective Cross Sections and Cadmium Ratios for the Neutron Spectra of Thermal Reactors," in "Proceedings of the Second United Nations Conference on the Peaceful Uses of Atomic Energy, Geneva, 1958," Vol. 16, Paper No. 202, p. 70, United Nations, Geneva, 1958. 
16. C. H. Westcott, "Effective Cross Section Values for Well-Moderated Thermal Reactor Spectra," CRRP-960, November 1960.

17. S. F. Mughabghab and D. I. Garber, "Neutron Cross Sections, Resonance Parameters," BNL-325, Third Ed. Vol. I, June 1973.

18. N. P. Baumann, "Resonance Integrals and Self Shielding Factors for Detector Foils," E. I. Dupont de Nemours and Co., DP-817, January $196 \overline{3}$.

19. A. Gibello, F. V. Orestano, F. Pistella, and E. Santandred, "Evaluation of Neutron Spectral Effects in Systems with Thermal Resonance Absorbers by Applying a Correlation Method to Measured Spectral Indexes" Nucl. Sci. Eng: 46; 61 (1970).
20. M. Brose, "On the Measurement and Calculation of the Resonance Absorption of Gold, Uranium, and Thorium Foils," Thesis, Technische Hochschule Karlsruhe, 1962

21. "Summary Documentation ENDF/B-IV," BNL-1 7541 (ENDF-201), Brook haven National Laboratory, October 1973.

22. G. Tessler and S. S. Glickstein, "Gamma-Ray Production Crošs Sections for Neutron Inelastic Scatlering frum $\mathrm{Cr}_{\mathrm{r}}, \mathrm{Ni},{ }^{92} \mathrm{Zr}$, and ${ }^{91} \mathrm{Zr}$ from 3 to $6 \mathrm{MeV}$," WAPD-T-2566, March 1975.

23. C. M. Lederer, J. M. Hollander, and I. Perlman, "Table of Isotopes," Sixth Ed., John Wiley and Euns, New Yurk, 1368. 


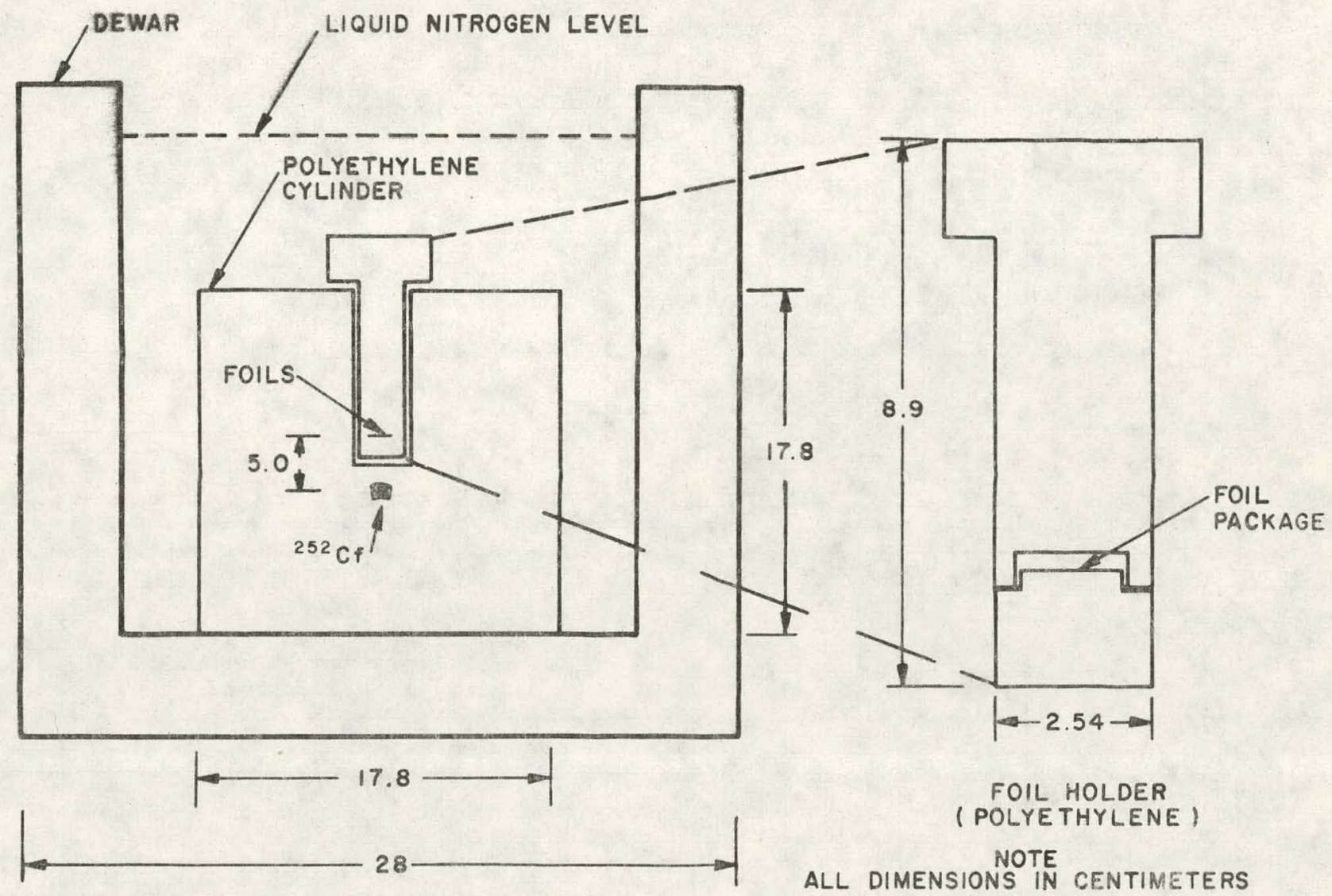

Figure 1. Irradiation System 


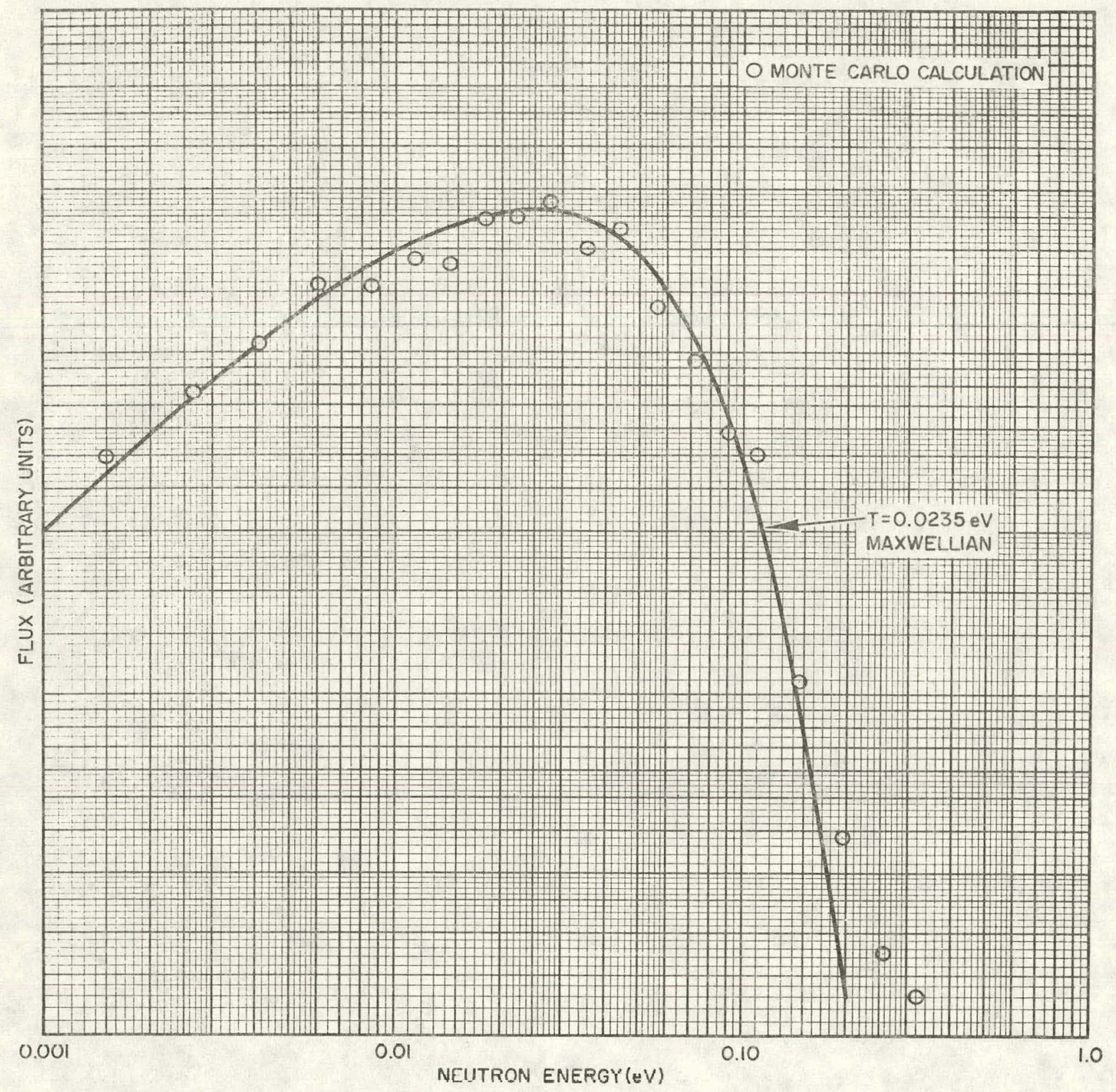

Figure 2. Room Temperature Polyethylene Flux $\left(T_{m}=0.0253 \mathrm{eV}\right)$ 


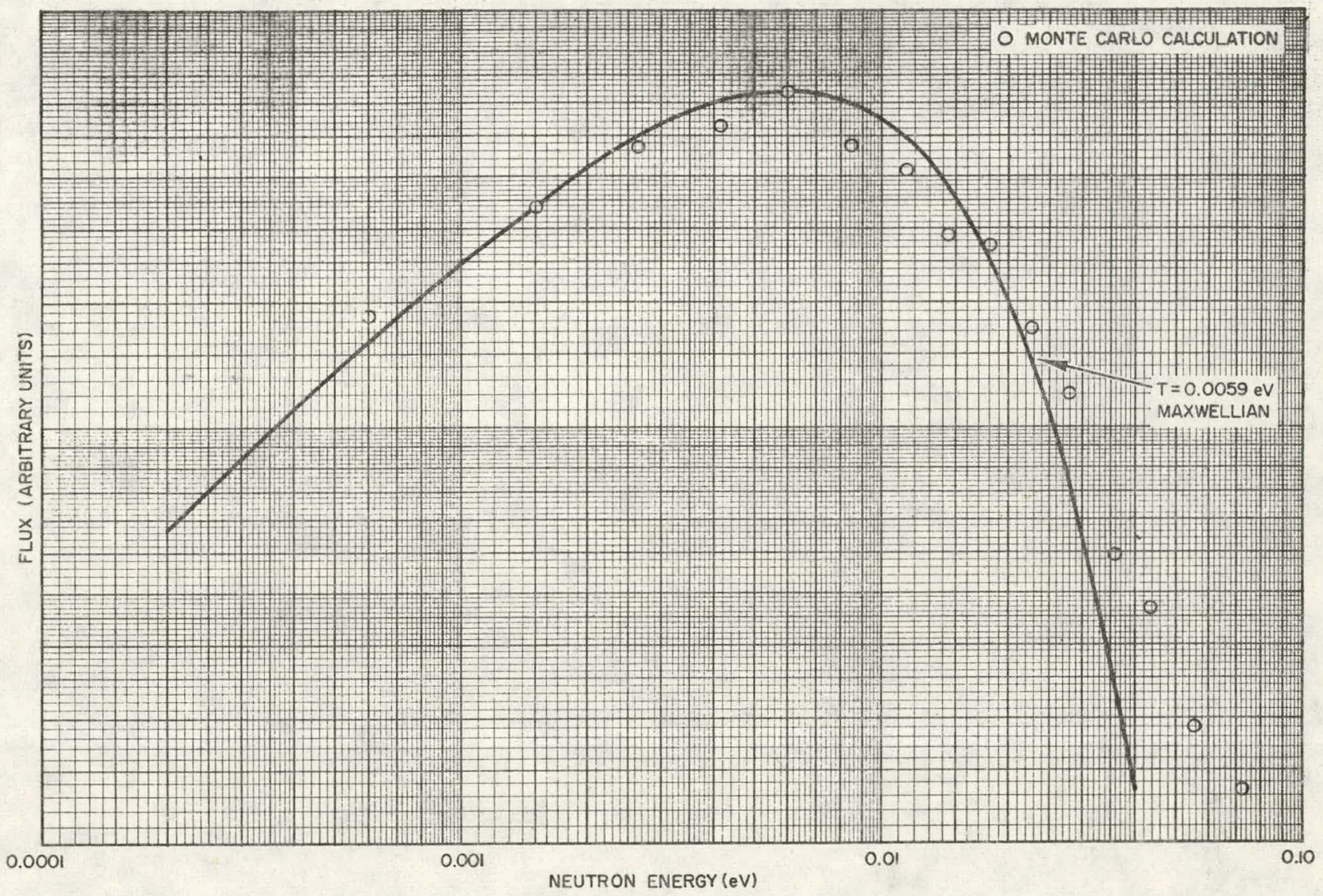

Figure 3. Liquid Nitrogen. Temperature Polyethylene Flux $\left(T_{m}=0.0066 \mathrm{eV}\right)$ 


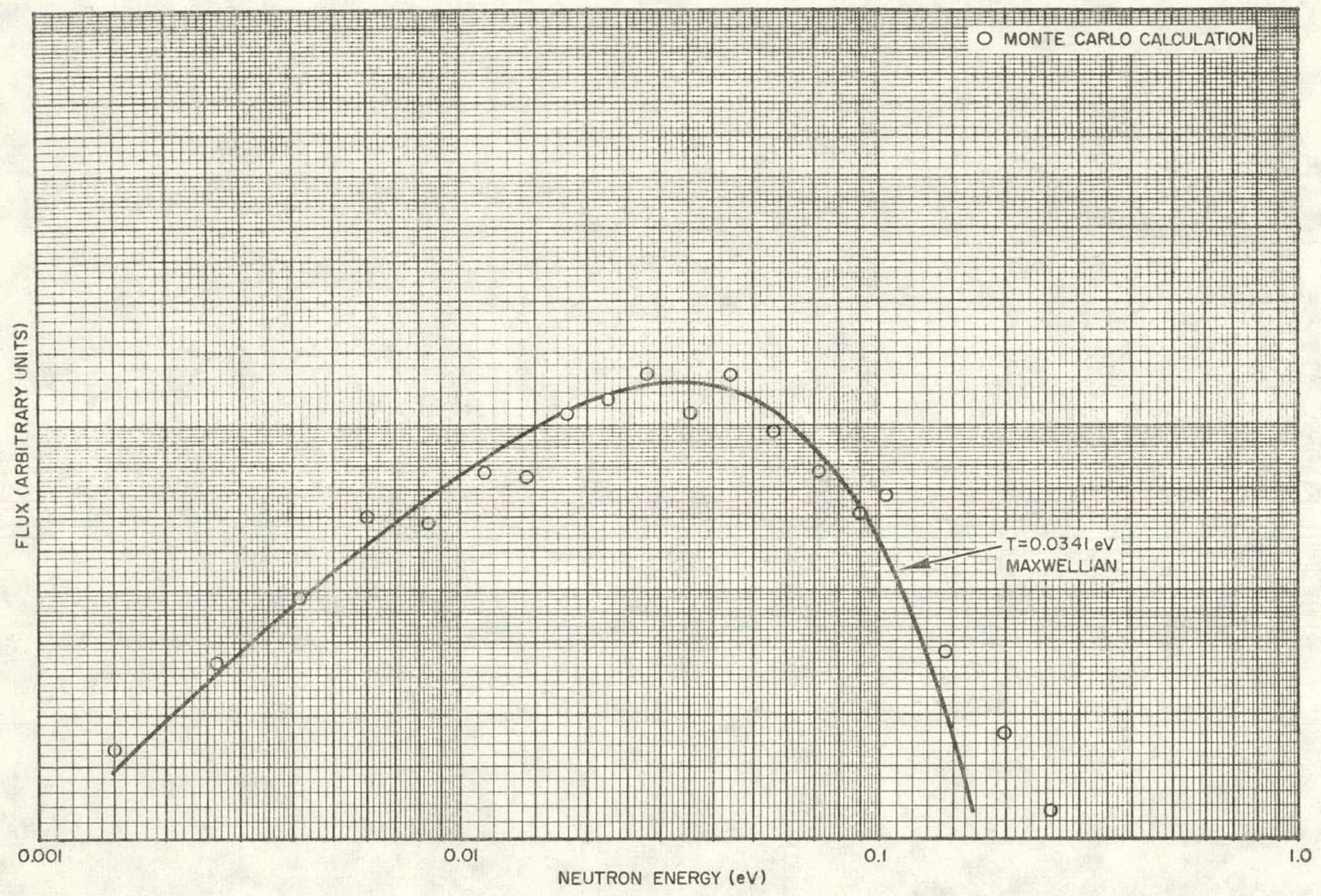

Figure 4. Boron-Poisoned Polyethylene Flux

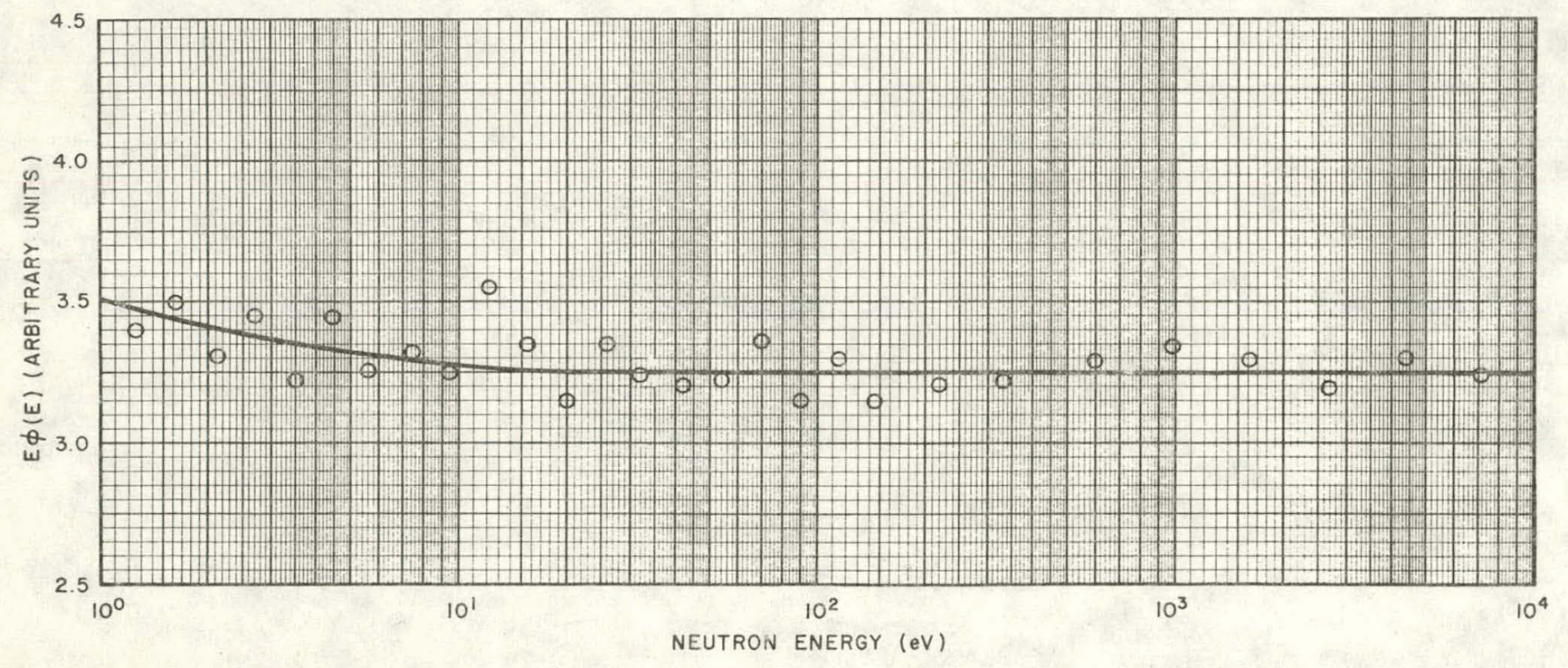

Figure 5. Room Temperature Polyethylene Resonance Energy Flux 


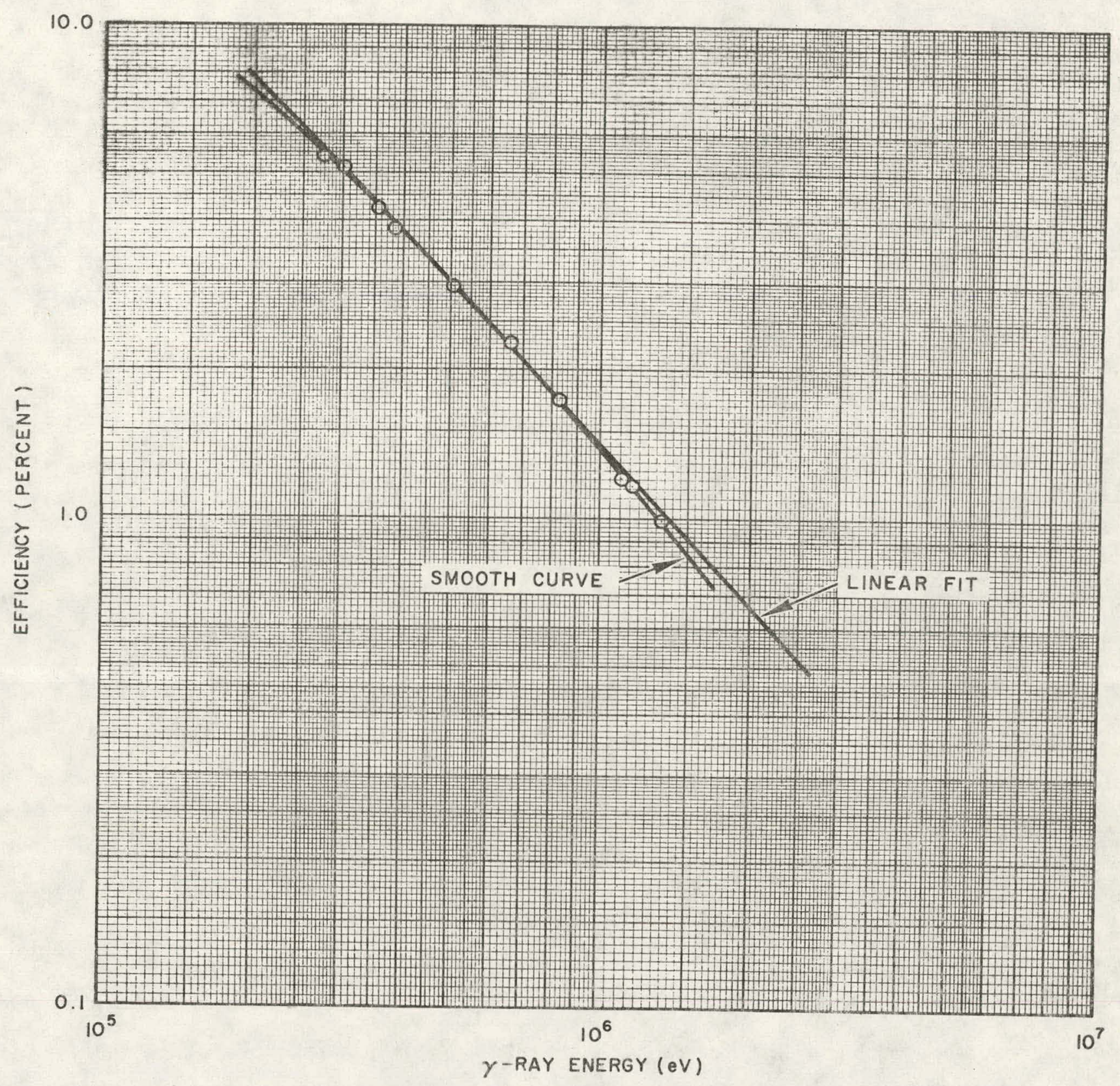

Figure 6. Ge(Li) Detector Efficiency 